\title{
OS ESTUDANTES GUARANI-KAIOWA DEFICIENTES E OS DESAFIOS DA EDUCAÇÃO ESCOLAR INDÍGENA
}

ÍRIS MORAIS ARAÚJO ${ }^{1}$

USP

\section{RESENHA}

BRUNO, Marilda Moraes Garcia; SUTTANA, Renato (Org.). Educação, diversidade e fronteiras da in/exclusão. Dourados: Ed. UFGD, 2012. 224 p.

O objetivo da coletânea que temos em mãos é contribuir, de maneira reflexiva, para a construção de políticas públicas que levem em conta o fato (espinhoso) de que a deficiência vem se tornando um desafio para diversas populações indígenas no país (VENERE, 2005; SANTANA, 2011; ANDRIOLI e FAUSTINO, 2012; BURATTO, s./d.; BURATTO e RESENDE DA COSTA, 2013; QUERMES e ALVES DE CARVALHO, 2013). As reflexões resultam de colaborações para o III

\footnotetext{
${ }^{1}$ Íris Morais Araújo é doutoranda (2010-2014) do Programa de Pós-Graduação em Antropologia Social da Universidade de São Paulo (USP) e bolsista CAPES. É graduada (2003) e licenciada (2004) em Ciências Sociais e mestre em Antropologia Social (2006) pela mesma universidade. Realizou estágiosanduíche (2013-2014) no Centre d'Enseignement et de Recherche en Ethnologie Amérindienne do Laboratoire d'Ethnologie et de Sociologie Comparative, instituição ligada à Université Paris X. É, ainda, pesquisadora do Centro de Estudos Ameríndios da USP e autora de Militão Augusto de Azevedo: fotografia, história e antropologia (2010). E-mail: irisaraujo80@ yahoo.com.br .
} 
ÍRIS MORAIS ARAÚJO - Os estudantes Guarani-Kaiowa deficientes e os desafios da...

Seminário de Pesquisa da Faculdade de Educação da UFGD, ocorrido em 2009, e do desenvolvimento do projeto Mapeamento de deficiências na população indígena da região da Grande Dourados: um estudo sobre os impactos e as possíveis implicações para a inclusão educacional, coordenado por Marilda Moraes Garcia Bruno (UFGD) e apoiado pelo Programa de Apoio à Educação Especial da CAPES.

O livro apresenta os resultados de incursões a questões concernentes à deficiência entre os Guarani-Kaiowa da Grande Dourados, correlacionando-as particularmente ao direito à educação formal das populações ameríndias. Tal preocupação reverbera, de saída, no artigo de Adir Cesaro Nascimento e Marina Vinha, que lista os principais marcos políticos e legais da escola indígena - "intercultural, bilíngue, específica e diferenciada" (NASCIMENTO e VINHA, 2012, p. 67) -, direito garantido na Constituição Federal de 1988.

Centrando a investigação no município de Paranhos (MS), Vânia Pereira da Silva Souza arrola os casos de Guarani-Kaiowa com deficiência. De um total de vinte pessoas distribuídas entre cinco aldeias, onze tinham disfunção neuromotora (mais conhecida como paralisia cerebral) e duas delas síndrome de Down. A desnutrição materna, da criança, traumas no parto, anóxia perinatal (falta de oxigênio ao nascer), prematuridade, infecções (rubéola, toxoplasmose, pressão alta, diabetes), meningites, sarampo e traumatismos cracioencefálicos são alguns fatores arrolados pelos agentes de saúde entrevistados para o alto índice da disfunção neomotora. No município em tela não há qualquer política pública de atendimento educacional especializado e, desses Guarani-Kaiowa, apenas seis frequentam a escola.

Já Michele Aparecida de Sá se ateve aos escolares com deficiência visual, tomando dezenove escolas indígenas de dez municípios da Grande Dourados. Por meio da avaliação de oftalmologistas, de um universo de 210 alunos, "foram encontrados 16 casos de deficiência visual" (SÁ e BRUNO, 2012, p. 146). A autora associa o índice, considerado alto, às más condições de vida da população GuaraniKaiowa da região da Grande Dourados. Não há ações desenvolvidas para garantir a permanência dessas pessoas na escola, de modo que a autora avalia que, na região estudada, "a interface entre a Educação Especial 
com a Educação Escolar Indígena ainda não foi construída" (SÁ e BRUNO, 2012, p. 160).

Por seu turno, Luciana Lopes Coelho, em diálogo com a literatura antropológica sobre os Guarani-Kaiowa, fornece pistas para compreender as questões dessa população frente à deficiência auditiva. A noção de pessoa do grupo fundamenta-se na ideia de nhe'e, termo polissêmico que significa palavra, voz, fala, alma, nome, vida, pessoa.

Ao nascer, o corpo da criança é possuído pela "palavra" (oñemboapika) que dá a vida a essa criança e a torna humana. Esta mesma palavra é "invocada" ao se nomear uma criança, e isso determinará a sua personalidade e a identificação com o grupo familiar. [...] O fato de "possuir a palavra" faz com que o sujeito "vivo" se diferencie dos que estão doentes, mortos ou que não possuem um "nome" (COELHO e BRUNO, 2012, p. 120).

Em pesquisa nos municípios de Amambaí, Paranhos e Coronel Sapucaia (MS), Coelho identificou oito pessoas deficientes auditivas. A autora considera a opinião de diversos indígenas entrevistados - dentre outros, lideranças, professores, Agentes Indígenas de Saúde, rezadores -, que afirmam que o fenômeno é recente e requer explicações diversas, que vão desde as más condições de vida enfrentadas pelos GuaraniKaiowa na atualidade até um castigo perpetrado por seres não humanos a casais tidos como malcomportados. Do ponto de vista da educação formal, a relação de ensino-aprendizagem tal qual praticada atualmente nas escolas indígenas não atende tais estudantes, haja vista que apenas duas delas, uma que utiliza aparelho auditivo e outra que possui perda auditiva leve, dominam a língua guarani. Em conversas com os pais dessas crianças, Coelho nota o esforço dos familiares em estabelecer a comunicação com seus filhos deficientes por meio de gestos, criando códigos, reforçando expressões faciais.

O potencial das Tecnologias da Informação e Comunicação (TICs) para deficientes auditivos - como "legendas (legenda explícita), closed caption (legenda oculta) e janela de interpretação" (SANTOS e SILVA DO NASCIMENTO, 2012, p. 202) - é o mote do artigo de Reinaldo dos Santos e Grazzielly Vilhalva Silva do Nascimento. A despeito de, muitas vezes, haver a disponibilidade desses recursos em ambiente escolar, os 
ÍRIS MORAIS ARAÚJO - Os estudantes Guarani-Kaiowa deficientes e os desafios da...

autores afirmam que há dificuldade no uso dos equipamentos e no domínio desse código. De modo geral, as práticas escolares continuam deixando de lado o aluno deficiente auditivo.

A pertinência das questões enfrentadas pelos autores - que parecem concluir alertando para a gravidade do problema e a falta de resposta das instituições escolares para o mesmo - não nos faz deixar de notar que muito pouco ainda se sabe da maneira com que os Guarani-Kaiowa pensam a deficiência, de que maneira lidam com ela no seu cotidiano e como avaliam a escola como parte da vida daqueles que são assim considerados. Diversidade, identidade, diferença, inclusão e exclusão não são termos estanques e, se informam concepções e práticas do mundo ocidental e moderno, não necessariamente fazem parte, com os mesmos sentidos, da imaginação conceitual indígena. Educação, diversidade e fronteiras da in/exclusão possui, dentre outros, o mérito de lidar com a questão com compromisso e pioneirismo, tornando-se assim uma referência a todos os interessados nos problemas que as populações indígenas vêm enfrentando nos dias de hoje.

\section{Referências bibliográficas}

ANDRIOLI, Luciana Regina; FAUSTINO, Rosangela Célia. Reflexões sobre o atendimento educacional especializado aos povos indígenas. Anais do Seminário de Pesquisa do PPE. Maringá (PR): UEM, 2012. p. 1-15.

BURATTO, Lúcia Gouvêa. A educação escolar indígena na legislação e os indígenas com necessidades educacionais especiais. s.d. Disponível em: http://www.diaadiaeducacao.pr.gov.br/portals/pde/arquivos/565-4.pdf. Acesso em: 23 fev. 2014.

BURATTO, Lúcia Gouvêa; RESENDE DA COSTA, Maria da Piedade. Alcoolismo e deficiência: formação de professores e agentes de saúde indígenas para a prevenção da síndrome alcoólica fetal. Anais do VIII Encontro da Associação Brasileira de Pesquisadores em Educação Especial. Londrina (PR): ABPEE, 2013. p. 701-710.

BRUNO, Marilda Moraes Garcia; SUTTANA, Renato (Org.). Educação, diversidade e fronteiras da in/exclusão. Dourados (MS): Ed. UFGD, 2012.

COELHO, Luciana Lopes; BRUNO, Marilda Moraes Garcia. O sujeito surdo na cultura 
ÍRIS MORAIS ARAÚJO - Os estudantes Guarani-Kaiowa deficientes e os desafios da...

Guarani-Kaiowá: o lugar da fala e da palavra na constituição do ser. In: BRUNO, Marilda Moraes Garcia; SUTTANA, Renato (Org.). Educação, diversidade e fronteiras da in/exclusão. Dourados (MS): Ed. UFGD, 2012. p. 115-138.

NASCIMENTO, Adir Cesaro; VINHA, Marina. A educação intercultural e a construção da escola diferenciada indígena na cultura Guarani-Kaiowá. In: BRUNO, Marilda Moraes Garcia; SUTTANA, Renato (Org.). Educação, diversidade e fronteiras da in/exclusão. Dourados (MS): Ed. UFGD, 2012. p. 63-84.

PEREIRA DE SOUZA, Vânia; BRUNO, Marilda Moraes Garcia. As crianças indígenas Guarani e Kaiowá com deficiência: ausências e emergências para a efetivação das políticas públicas de saúde e educação. In: BRUNO, Marilda Moraes Garcia; SUTTANA, Renato (Org.). Educação, diversidade e fronteiras da in/exclusão. Dourados (MS): Ed. UFGD, 2012. p. 85-114.

QUERMES, Paulo Afonso de Araújo \& ALVES DE CARVALHO, Jucelina. Os impactos dos benefícios assistenciais para os povos indígenas: estudo de caso em aldeias Guaranis. Revista Serviço Social \& Sociedade, São Paulo (SP), n. 116, p. 769791, 2013.

SÁ, Michele Aparecida de; BRUNO, Marilda Moraes Garcia. Escolares indígenas com deficiência visual: das políticas públicas às especificidades socioculturais. In: BRUNO, Marilda Moraes Garcia; SUTTANA, Renato (Org.). Educação, diversidade e fronteiras da in/exclusão. Dourados (MS): Ed. UFGD, 2012. p. 139-178.

SANTANA, Sirlândia. Imagem e autoimagem da pessoa com deficiência na comunidade indígena: um estudo da etnia Tupinambá em Olivença-Ilhéus-Bahia. Revista Ibero-Americana de Estudos em Educação, Araraquara (SP), v. 6, n. 3, p. 102-114, 2011.

SANTOS, Reinaldo dos; SILVA DO NASCIMENTO, Grazielly Vilhalva. Educação, inclusão e TICs: o uso de tecnologias da informação e comunicação como recurso para inclusão de deficientes auditivos. In: BRUNO, Marilda Moraes Garcia; SUTTANA, Renato (Org.). Educação, diversidade e fronteiras da in/exclusão. Dourados (MS): Ed. UFGD, 2012. p. 139-178.

SUTTANA, Renato (Org.). Educação, diversidade e fronteiras da in/exclusão. Dourados (MS): Ed. UFGD, 2012. p. 199-220.

VENERE, Mario Roberto. 2005. Políticas públicas para populações indígenas com necessidades especiais em Rondônia: o duplo desafio da diferença. 2005. $139 \mathrm{f}$. Dissertação (Mestrado em Desenvolvimento Regional e Meio Ambiente) - NCT, UNIR, RO, [2005]. 